\title{
Consolidation in the UK commercial radio sector: the impact on newsroom practice of recent changes in regulation, ownership and the local content requirement
}

\section{Introduction}

This paper aims to explore the implications for the UK commercial radio industry of a series of changes to the regulation of the sector since it was first established in the 1970s. Each change to the regulatory environment brought with it a relaxation of the initially very demanding public service requirement on the sector and, in particular, a new focus on product rather than process has enabled the ownership groups of stations to move not also programming production but also much news journalism out of the editorial areas it is intended to serve, and into news 'hubs' intended to rationalise the process of news gathering and bulletin presentation and enable the groups to become increasingly profitable. The paper will consider a number of issues around the management of commercial radio groups in the UK, the development and, most recently, exploitation of the group ownership system of what mainly began as locally-owned and locally-operated radio stations, each with a distinctive character of its own and a commitment to meeting the specific needs of the editorial area it was intended to serve (Starkey, 2015), and the appropriateness of the current regulatory regime in the much-altered media landscape of today.

When legal, land-based, but originally only local commercial radio began in the United Kingdom in the 1970s (Baron, 1975), tough regulation ensured radio stations kept to promises made in the 'beauty contest' selection processes leading to the awarding of radio broadcasting licences, around the production of news and other forms of local speech content. Without exception, the stations had to produce local news locally, and even the duration of news bulletins and extended news programmes was controlled very tightly by the first regulator of the sector, the Independent Broadcasting Authority (IBA). While the first stations to be awarded the franchise to provide an Independent Local Radio (ILR) service to a particular area were deemed large enough and potentially well-funded enough to compile hourly bulletins in their own newsrooms, the second wave of franchise awards introduced a number of medium-sized stations that were constrained not only in the broadcasting hours they were trusted to broadcast - some closing down late evenings - but also in terms of the autonomy of their newsrooms. For example, stations such as Marcher Sound in Wrexham and Deeside which first broadcast in 1983, were obliged to relay every hour the three-minute bulletin of national and international news supplied to them via broadcast quality 'music lines' by Independent Radio News (IRN) in London, and then to follow it with two minutes of locally-originated news, presented in as similar a style as possible to IRN's often more professional-sounding delivery. Since then, many changes to broadcasting regulation have occurred - especially in radio - in particular divesting stations of significant and essentially burdensome requirements around their public service obligations, local ownership and local content production. One reason for this was that the commercial radio network grew much larger than was originally planned, so that an original target of 60 local stations was surpassed several times over, and by the 1990s a nightmarish situation had evolved in which layers of national, regional and local stations were all in competition with each other and with other media for dwindling amounts of advertising revenues. The economic challenges of this more competitive market than was originally envisaged enabled station owners to then plead for regulation to be relaxed on economic grounds.

Those economic challenges regarding what may be produced locally without the smallest of stations going bust (Day, 2006), and the understandable desire of commercial radio proprietors to make a profit from their investment in the stations have progressively lowered 
government and hence, regulatory expectations around the provision of large amounts of locally-produced speech content on every station. Tony Stoller, once a station manager, then Chief Executive of the next regulator of the sector, the Radio Authority, from 1995-2003, identifies a conference of ILR managers at Heathrow in 1984 as the pivotal moment at which the industry began to formally resist heavy-handed regulation and assert a claim to be allowed to develop along more commercial, more profit-driven and in turn less public service-oriented lines (2010: 142-53). On ownership, the principle of local control was soon abandoned and a snowballing process of mergers and acquisitions in the 1980s and 1990s led to the formation of a number of large groups of stations (ibid 244-59). As new ILR licences and new types of licences in terms of scale, ('incremental', regional and 'small-scale alternative' or 'sally',) were advertised, it became commonplace for a group to win the beauty contest to provide a commercial radio service in a newly-defined area, rather than a consortium of local business interests and other local stakeholders, as had initially been the case and, it must be said, the vision.

Meanwhile, a series of advances in production and distribution technology over the period have resulted in radical changes to the ways in which the sector is operated, within the lessening constraints of the prevailing regulation. Such technological advances are particularly apparent in the provision of news, which now exploits synergies in group ownership and new forms of content sharing that were once unimaginable. A number of commercial radio groups now operate news 'hubs' which take journalism out of the editorial area while concealing this practice from their listeners (Crisell \& Starkey, 1998: 16-26). In addition, the provision of national and international radio news to all the UK's licensed commercial radio stations, (once the remit of the independent company, IRN, a subsidiary of the first ILR station to launch in 1973, the news and talk station LBC in London,) has become a monopoly of the satellite broadcaster, Sky. Notionally, IRN still provides the service, but today it is contracted out to Sky, who supply a service of copy, audio cuts and hourly bulletins for stations to carry if they so wish, as a by-product of their rolling news television channels Sky News and Sky Sports News. Because the UK has, therefore, only two sources of national and international radio news, Sky and the BBC, this further relaxation of regulation of the commercial sector is seriously restricting pluralism in radio news. Paradoxically, it would be widely considered to be intolerable for there to be only two national newspapers in a country the size of the UK, especially if one of them were owned by an Australian with citizenship of the United States.

The principal aim of this paper, though, is to investigate the ways in which changes to regulation of the commercial radio sector have impacted upon local radio news journalism, albeit mixed with some relative proximity as it inevitably still is, with national and international news which almost always originates from outside individual editorial areas, be they in Liverpool or Linlithgow, Ludlow or Lincoln, or elsewhere. So, in meeting that aim, the paper will consider three hypotheses:

- Radio news journalism in the United Kingdom is becoming increasingly centralised into at best regional, and at worst, even more remote, news 'hubs'.

- The relaxation of broadcasting regulation has diminished the impact of local radio news in an increasingly varied, pluralistic and, inevitably, competitive, media landscape.

- A duopoly of national and international news production in radio broadcasting has developed which would not be tolerated in other traditional and emergent media.

\section{The wider contexts for UK commercial radio - historical and technological}


As we relate the situation today to its historical roots, though, we are most certainly not suggesting that radio once enjoyed a golden age, which has long since expired. We recognise that the whole media landscape has changed, and with contextual change must come a response. There is much about the choices on offer to radio audiences of today that represents a significant improvement on what went before, as even a cursory reading of historical texts would confirm, revealing as it would a dearth of listener choice among a relatively small number of services operated by the BBC, the continental broadcasters of the 1920s and 1930s such as Radio Luxembourg and Radio Normandy, and the offshore pirates of the 1960s and 1970s (Briggs, 1961; Crisell, 1994). The growth in the number of radio services in the UK in recent years is particularly evident in the way that the relative success of digital radio has increased the range of choice available to radio listeners, who can now choose between many more niche music services than ever before. In no other country has a single digital radio platform been adopted by the public so enthusiastically as in the UK, where Digital Audio Broadcasting (DAB) now accounts for a $25.9 \%$ share of all radio listening (RAJAR 2015). One example of the increase in choice is the newly national scale of LBC, launched in 1973 as a news and talk service for London, with the ability to focus from time to time on issues of interest only to Londoners. Now available nationwide on the first commercial DAB multiplex, LBC now enriches the choice of listening available across the country, but as a consequence of expanding its coverage, this is no longer a service targeted only at London. $\mathrm{DAB}$ is, though, not the only relatively new platform for the distribution of radio services. The internet, with the increased capacity of broadband and fibre optic cable, as well as the proliferation of mobile devices, with their use of wifi and mobile phone connectivity, have been additional catalysts for the recent changes to the media landscape as it relates to choice in radio listening. Radio, though, is not the only medium to which local audiences can now turn in order to access local information, of which there are now many more sources than when commercial radio began - including television and local newspaper websites, hyperlocal news websites and GPS or IP address-dependent automatic news aggregators that automatically populate pages with local content targeted at individual internet users whose location is apparent to the aggregator. It could, therefore, be argued that the presence on radio of local news is less important now, than when the only local media for local audiences to turn to were the local radio station and the local press. Even if today we are not witnessing a 'golden age' of local radio journalism, it may well be a golden age of local journalism. However, as the concern of this paper is local radio journalism, it will explore and place on record the implications of change for the practice of radio journalism at local levels. This will be explored in detail in the final section of the paper, as a result of a thorough and wideranging survey of the situation in November 2014, which the authors jointly undertook.

Firstly, some more detail of the historical context. After the offshore pirate stations, (including the most popular, Radio Caroline and Radio London,) were made illegal in 1967, a change of government in 1970 led to legal commercial radio being introduced in 1973, initially allowing only locally-owned and locally-produced stations to finally bring about the end of the BBC's monopoly of domestic radio. By 2014 the third, and most recent of the broadcasting regulators for the commercial radio sector, Ofcom, had responsibility for 338 licensed commercial local radio stations, in a country with a population of only 63 million. That is many more than the original sixty stations that had been proposed back in the 1970s, and the earlier observation about competition for audiences in a radio marketplace that has become increasingly crowded is underlined by the existence since the 1990s of three national commercial stations. There are now a total of eight national radio stations broadcasting on analogue FM or AM frequencies, each with a further presence on DAB and through online and mobile platforms - five of them run by the $\mathrm{BBC}$ and three by private companies. The $\mathrm{BBC}$ also operates 40 local radio stations of its own, (although recent cost-cutting has 
resulted in increased amounts of shared programming across them,) together with regional stations in English, Welsh and Gaelic for the semi-autonomous regions of Scotland, Wales and Northern Ireland. No longer is radio listening confined to the FM and AM broadcast bands, though, nor even to DAB. Radio is now commonly available on such platforms as social networking sites, mobile phones, tablets, web sites and television EPGs, and use of these different platforms is increasing (RAJAR, 2015). It may also be that this is the golden age of radio.

\section{The relaxation of regulation: a focus on product rather than process.}

Here lies the problem for local radio journalism. Many of those commercial local stations now share programming because a number of the large groups that began to form in the 1990s, (as financially more robust stations bought more vulnerable ones,) have exploited progressive relaxation of the regulatory environment to make their businesses more financially viable. This means that very few of those supposedly local radio stations are now programmed locally throughout even the daytime, and increasingly news production has been taken out of the individual radio stations and relocated to dedicated news centres or 'hubs', some of them within the same region, and others even farther away. Significantly, this is taking the local journalism out of the local editorial area. As the cost implications of producing the large amounts of locally-based programming they had promised in order to win licences, began to affect the viability of growing numbers of smaller stations outside the major conurbations where ILR had begun, some groups looked for alternatives. At times of challenging economic circumstances this issue became more acute, and in 2006 one group, UKRD, returned to Ofcom the licence to operate its station in Stroud, which had been using the Star FM brand (Day, 2006).

Ofcom had already signalled its intention to relax the regulatory focus on process, (that is, the logistics of content production,) and concentrate instead on the product, by publishing a document entitled Radio - Preparing for the Future (Ofcom, 2004). This meant that as long as broadcast content sounded local, the manner of its production was of less concern. With the threat of more licences being returned, Ofcom became far more lenient than could ever have been imagined of its predecessors, the IBA and the Radio Authority. By now the technology of radio production had become so advanced that automatic switching between local and remote studio output was imperceptible to audiences, who can now very easily be tricked into believing that content that is either pre-recorded or originates from outside the area, sounds like it is live or local, or both. So, a now common response that can be authorised by Ofcom at its discretion is the practice of 'co-locating' more than one station in a single studio building, even though one or or more of the stations produced there serve editorial areas which lie some distance away. This is perhaps the ultimate deception in local radio, in that it sounds local, but in very few senses of the word can it really be said to be of the area. A key expectation of the regulator in permitting co-location of services by groups is that audiences should remain unaffected by it, so unaware of what has happened to their local radio station, and therefore indifferent to the change. A notable exception to this principle was adverse publicity attracted by the sudden co-location by Bauer Media of TFM on Teesside to its Metro Radio studios in Newcastle in 2013, even though every day several hours of programming on the two stations were already being shared and the news on TFM had been 'hubbed' for some time. What some members of the audience objected to, when they heard on social media what was happening, was the loss of their 'own' local radio station, one which had developed considerable 'heritage' brand loyalty since the 1970s - even though in reality, for some time prior to the move, they had only been benefiting from local breakfast and afternoon drive time programmes anyway. Paradoxically, listening figures, which had 
seen the station lose 33,000 listeners the previous year, showed an improvement in weekly listener reach during the first quarter after the merger (RAJAR, 2013).

The first use of genuine news 'hubs', (in the sense that a 'mother hen and chicks' model was introduced in order to concentrate news production in one place in a region, while retaining some local autonomy and peripatetic news reporting in each of the stations supplied by the hub,) was in South-West England in 2002 (Crisell \& Starkey, 2006: 20-1). One of the last initiatives of the previous regulator, the Radio Authority, was to allow the then largest commercial radio group, GWR, to experiment with a hub that served five previously quite separate stations: Plymouth Sound, Gemini FM (Exeter), Orchard FM (Taunton), South Hams Radio (South Devon) and Lantern FM (North Devon). The only requirement on the group was that a 'local journalistic presence' was maintained in each local area, while the process of bulletin editing and presentation for each station was undertaken at the central newsroom established at the hub. Listeners to a station served by the hub, on hearing a news bulletin apparently being read live on the hour, would not realise it had been recorded perhaps ten minutes earlier somewhere relatively far away, by a newsreader who then went on to pre-record similarly localised bulletins for other stations owned by the same group. It is worth considering what a 'journalistic presence' in each of the areas served under such an arrangement might entail, and to what extent that presence would be expected to be 'continuous'. GWR was taking the first tentative steps along a path that, with the blessing of the Radio Authority and then, from 2003, Ofcom, has by now become commonplace in UK commercial radio. That initial, relatively cautious experiment was one that both group and regulator were keen should succeed, but today the journalistic presence in each local area served by a centralised hub is often sporadic, with perhaps only a single journalist on the patch, and not necessarily all day, every day of the week. Before Ofcom even came into being, as one of the consequences of the Communications Act 2003, the case for news hubs had been eloquently put, and the experiment had already been declared a success.

\section{News hubs in the UK commercial local radio sector: November 2014}

For the purposes of this research into the contemporary use of news hubs, the focus remained on the local licences issued mainly under the very different circumstances of the preceding forty years, and therefore considering the impact 'hubbing' has on local, rather than regional or national, commercial radio. Because radio's peak listening hours are during daytime, that focus is also upon those stations' broadcast output from $6 \mathrm{am}-6 \mathrm{pm}$, as the economics of the commercial radio sector mean the long standing practice of local commercial radio stations using the IRN hourly bulletins during evenings and overnight persists, even though they are now provided for IRN under licence by Sky News Radio. Ironically, though, most of those radio stations were licensed on the basis of a promise of performance to whichever regulator originally licensed them, be it the IBA, the Radio Authority or Ofcom, to produce a certain amount of genuinely local news as a condition of retaining their licence. In the majority of cases, the original licensing process was a competitive one, and unsuccessful bidders were turned down who may now have a legitimate case for complaint, that essential criteria for previous licence awards have now largely been forgotten.

This research also distinguishes between the different practices of co-location and hubbing, the first of which describes the situation of two or more whole radio stations being produced in one building, in the manner discussed earlier in the case of Metro and TFM in North-East England. Inevitably, co-location means the output of one or more 'local' radio stations comes from somewhere else, which rather disrupts any reasonable notion of such stations being local in any meaningful sense. Conversely, hubbing refers only to news journalism, where in some cases each radio station's non-news programming output continues to be broadcast, at 
least for part of the broadcast day, from one building situated inside the editorial area - while of course, if hubbed, some or all of the news output which complements the programming is produced in a newsroom elsewhere. This is a fast-moving industry, in which mergers and acquisitions of individual stations and even whole groups can alter the landscape without notice, so in order to identify current practice, the methodology adopted for this research involved taking a snapshot of the use of news hubs by the 16 local commercial radio groups operating in the UK during the month of November 2014. The findings are summarised in table 1.

\begin{tabular}{|c|c|c|}
\hline Radio group & \begin{tabular}{|r|} 
Original \\
local \\
$\mathrm{AM} \mathrm{or}$ \\
$\mathrm{FM}$ \\
licences
\end{tabular} & Newsrooms or news 'hubs' \\
\hline Anglian & 5 & 1 hub: all 5 stations from Ipswich \\
\hline Bauer & 34 & $\begin{array}{l}2 \text { main hubs: Manchester } \& \text { Glasgow }+1 \text { part-time hub: } \\
\text { Leeds }+3 \text { separate newsrooms }+1 \text { co-location: Metro/TFM }\end{array}$ \\
\hline Celador & 8 & 3 hubs: Bristol, Southampton, Andover \\
\hline Cheshire & 2 & 1 hub: both stations from Chester \\
\hline CN Radio & 3 & 1 newsroom: Belfast +1 hub for $2 \mathrm{NW}$ England stations \\
\hline Communicorp & 1 & Station operated under licence by Global \\
\hline Global & 74 & Estimated 19 hubs \\
\hline KM FM & 7 & 1 hub in Medway \\
\hline Lincs FM & 8 & 3 hubs: Lincs FM, Hull, Doncaster \\
\hline Orion & 9 & 1 hub: Birmingham \\
\hline Quidem & 6 & 1 hub near Kenilworth \\
\hline Tindle & 2 & 2 newsrooms (sharing Channel Island stories) \\
\hline TLRC (UKRD) & 10 & 9 newsrooms, some sharing at weekends \\
\hline Town \& Country & 6 & 1 hub: Cardiff \\
\hline UKRD & 5 & 4 newsrooms; KLFM hubs for Star Cambridge \\
\hline UTV & 14 & 1 co-location of 3 stations in Wigan +8 newsrooms \\
\hline
\end{tabular}

Table 1: Summary of news hub usage by the 16 UK commercial radio groups, November 2014 (Source: own research)

The methodology adopted for gathering this data was a combination of interviews with individual news editors or others in senior management positions at group level. Where it was felt necessary, some of the information was then verified where possible in order to triangulate the data and corroborate the findings. The approach differed from to group to group depending on the willingness of the stations to provide the information. At the time of writing, Global was the one group which had presented particular challenges to the project, because despite repeated calls and emails, including to the group Head of News, James Rea, 
they appeared reluctant to share their arrangements. It is perhaps understandable that the largest, and therefore most conspicuous of the groups, (which also operates the UK's only national commercial FM radio station, Classic FM,) should choose to keep certain logistical aspects of its operation backstage. They were, after all, the pioneers of mass rebranding of once distinctive local and regional stations with, in some cases, decades of local heritage to their credit, turning them into virtual clone services under the now quasi-national brands Capital, Heart and Smooth, which share as much programming as the regulator allows (Starkey, 2015: 157-9), a shrewd business model that has nonetheless attracted some criticism. In the South-West, for example, each of those stations previously involved in the 2002 experimental news hub were all rebranded as Heart shortly after the acquisition of GWR by Global. Paradoxically, it could be argued that these analogue broadcasting stations use a still finite public resource, the electromagnetic spectrum allocated to FM and AM radio, and that the public have a right to know how they are being used. Furthermore, concealing such information from the public, be they academic researchers or not, does run counter to the spirit of journalistic endeavour which motivates their own daily newsgathering.

While Global is the UK's largest commercial radio group, holding 74 local licences as well as the national commercial licence operated under the Classic FM brand and a number of digital stations, its nearest rival, Bauer, holds 34 such local licences and operates a number of national digital radio stations distributed on such platforms as DAB, the internet and digital television. Although because of its size, Global would immediately appear to be the most prolific user of hubbed news output, in reality - and despite our not being given access to the level of precise data this research was seeking - pro rata its use of hubs might not be the most excessive in the sector. Despite the group's current house style being for all its bulletins to end with the phrase "From Global's newsroom", this complex network is one of different logistical combinations that may see one station broadcasting a series of genuinely local hourly news bulletins, produced by a journalist working at the station for part of the day, and then at another time its bulletins being produced from a location many miles away from the editorial area by a team who are also responsible for five or six other stations' news output that hour. This practice of switching between hub and local newsroom operation is not confined to Global, and it is commonly related to time of day, as local news may assume greater importance during the traditional peak periods of listening at breakfast time, midmornings and afternoon drive.

Bauer's main hub in Manchester provides bulletins for 14 stations, most of which are analogue licences in the North of England - although some are national digital stations which are national in both coverage and character. (Bauer also operates one of the UK's two analogue commercial national radio stations on AM, Absolute Radio.) They receive bulletins of only national and international news from the hub and their audiences aren't given any expectation of local content. However, listeners of Hallam FM in Doncaster might reasonably expect their news is being produced in a newsroom in neighbouring Sheffield, where the station's studios are located, rather than 50 miles away in Manchester. Audience expectations of their local station may not have altered since the end of the 1990s when Gage (1999: 58) explained the unique selling point of a local station thus: "While a bulletin will cover international news, the listener expects a local station to present relevant weather and travel information as well as the local news - indeed, that is one of the strengths of local radio." The Bauer group stations served by the hub in Salford derive some localness in their bulletins from lone peripatetic reporters operating in those stations' editorial areas. These reporters communicate with the hub via email and are often included in a morning news conference, in which they participate by telephone. They provide story ideas to the hub by relying on traditional sources and local knowledge as well as on social media and other online sources. 
They might also be asked by the hub to cover a particular story, for example knife crime, from a local perspective and that same story could be used throughout the group but with differing local content on each local station, provided by each patch reporter and edited into the reports at the hub. Financial pressure may have persuaded the big groups to use hubs, but as well as it remaining a regulatory requirement in most cases, it appears they still realise the value of perceived localness. "Radio editors talk ...about 'owning your patch'. The idea is to win the trust and respect of your listeners. You are the one who tells them if schools are closed when it snows, if roads are blocked or if power is down" (Hudson \& Rowlands, 2012: $37)$.

The third largest group, UKRD, owns and operates 15 local radio stations across England, 10 of them through a different group of which it acquired control in 2009. UKRD takes a very different approach to local radio journalism, and almost every station has its own newsroom. Throughout the week they prefer to run a local newsroom-based service, although at weekends a single newsroom in a region may take on the responsibility of providing news to neighbouring stations. The group clearly faces the same financial challenges as its rivals, however after a short period of more widespread hubbing they returned to the pre-2002 newsroom practice of using only local provision. The necessary compromise to this is that news teams in each station are tiny, and it is not unusual for a single journalist to be solely responsible for the station's news output throughout the majority of a shift. This poses particular challenges in breaking news or when a journalist needs to go to an important press conference and there is no option but to leave the newsroom unattended. A journalist out of the office on a story has to keep a close eye on breaking news and other developments in continuing stories to ensure their already pre-recorded bulletin isn't suddenly becoming out of date, or worse, factually incorrect or legally unsafe. If a suspect were to be arrested in an ongoing crime story and the bulletin then didn't reflect the change in status of the criminal matter to an 'active' case, the journalist could later be found to be in contempt of court.

Local radio journalists in such stations are faced with a paradoxical challenge, which is that although their news is local, (in that it is being produced and broadcast locally by someone who lives locally,) the bulletin may not sound as local as a hubbed station's output. A journalist who is forced into an increasingly desk-bound role for the logistical reasons explained previously, will often be more reliant on IRN copy and audio to fill bulletins with content. As radio journalists are often relatively transient people who tend to move stations every few years, it is likely that locally-produced bulletins are nonetheless read by journalists from outside the area and don't include any local voices at all. The inclusion of local voices, stories and place names is something a local news editor will remind new staff to aim for, in order to ensure that listeners feel that theirs is a station for them and of the area (Hudson \& Rowlands, 2012: 22). Representation of local voices was one of the motivating factors in the popularising of the radio phone-in in the 1970s (Starkey, 2015: 98) and it is a powerful way for a local radio station to connect with an audience and to encourage that audience to feel a sense of ownership and loyalty to the station. In an interview with a UKRD radio journalist we learned that this loyalty and sense of pride that local people have in 'their' station is an important factor in encouraging potential interviewees to come into the studio to be interviewed, which avoids the journalist having to leave the local newsroom.

With 14 stations, mainly in smaller urban areas such as Stoke-on-Trent, UTV Radio retains a number of local newsrooms which also hub for other, nearby stations in the group. (UTV also runs the third national analogue station, talkSPORT, which, like Absolute Radio, broadcasts on AM as well as on digital platforms.) In its 'news mission statement', UTV insisted that at least one of the top three stories in any bulletin should be local, with 70 per cent local content in breakfast-time bulletins. Interestingly, despite the high profile attracted by the rebranding, 
co-location and programming syndication that have become synonymous with the largest groups, it is in the smaller groups that we often found the greater use of hubbing pro rata to the number of licences held. The Anglian Radio Group, for example, simply runs one hub for all its five licences. Orion rus a single hub for all its nine stations and Quidem one hub for all six licences, exploiting the regional nature of their operations. Similarly, Town and Country has a single hub in Cardiff for a total of six stations, but it is worth noting here that the smaller groups are also limited in the size and financial turnover of their stations, being based mainly in editorial areas with relatively small populations, making financial viability much more of an issue for them than for the bigger groups who now have the potential to generate large profits from their commercial radio interests.

\section{Conclusion}

Localising national stories is a practical approach that predates the introduction of news hubs, but it is a particularly useful practice, both for hubs serving large numbers of dependent stations and for critically under-resourced local newsrooms. It bears comparison with the wider phenomenon of glocalisation, and it comes highly recommended, as long as the localising element is not excessively tenuous, as Hudson and Rowlands noted: "The more local people and places mentioned in your bulletin, the more 'talkability' the station gets" (2012: 37). The original research underpinning the survey carried out for this article identified widespread use of hubs in the UK commercial local radio sector in order to preserve the local content in news bulletins still required by the sector's third-generation regulator, Ofcom, while simultaneously achieving considerable economies of scale by exploiting successive relaxations of regulation around the processes through which localness in local radio is created. Furthermore, the sector relies heavily on national and international news sourced by Sky and either relayed as unadulterated bulletins during off-peak hours or mixed in local newsrooms and centralised hubs with local or localised material. Because the only other source of local and international news in UK radio is the BBC, this apparent duopoly is anti-competitive and would not be regarded as healthy in any other medium in a democratic society. We conclude, however, that the media landscape has changed dramatically since the inception of ILR in the 1970s, and although the element of truly local production in local radio journalism may have diminished since the 1980s and 1990s, greater access to other sources of local news and information may mean that the progressive changes to content regulation of the sector may be justified, especially in the case of smaller stations than were originally envisaged in the 1970s that would otherwise struggle to survive the competitive media market of today.

\section{References}

Baron, M. (1975) Independent Radio, Lavenham: The Lavenham Press.

Briggs, A. (1961) The History of Broadcasting in the United Kingdom: Volume I - The Birth of Broadcasting, Oxford: Oxford University Press.

Crisell, A. (1994) Understanding Radio (2nd edn), London: Routledge.

Crisell, A. \& Starkey, G. (2006) 'News on local radio' in Franklin, B. (ed.) Local Journalism and Local Media: Making the Local News, London: Routledge.

Day, J. (2006) 'FM licence thrown back at Ofcom', The Guardian, 21 September http://www.guardian.co.uk/media/2006/sep/21/commercialradio.radio1

Gage, L. (ed.), Douglas, L. \& Kinsey, M. (1999) A Guide to Commercial Radio Journalism $\left(2^{\text {nd }}\right.$ edition) Oxford: Focal Press. 
Hudson, G. \& Rowlands, S. (2012) The Broadcast Journalism Handbook (second edition), London: Longman.

Ofcom (2004) Radio - Preparing for the Future, London: Office of Communications.

RAJAR (2013) Quarterly Survey, (first quarter), London: Radio Joint Audience Research.

RAJAR (2015) Quarterly Survey, (first quarter), London: Radio Joint Audience Research.

Starkey, G. (2007) Balance and Bias in Journalism: Representation, Regulation and Demcracy, Basingstoke: Palgrave Macmillan.

Starkey, G. (2015) Local Radio, Going Global (paperback edition), Basingstoke: Palgrave Macmillan.

Stoller, T. (2010) Sounds of Your Life: A History of Independent Radio in the UK, New Barnet: John Libbey Publishing. 